\title{
Wheel running increases hyperthermia and mortality rate following 3,4- methylenedioxymethamphetamine (MDMA) in rats
}

M. A. Taffe

Department of Neuroscience; The Scripps Research Institute; La Jolla, CA, USA

Address Correspondence to: Dr. Michael A. Taffe, Department of Neuroscience, SP30-2400; 10550 North Torrey Pines Road; The Scripps Research Institute, La Jolla, CA 92037; USA; Phone:

+1.858.784.7228; Fax: +1.858.784.7405; Email: mtaffe@scripps.edu 


\section{Abstract}

Hyperthermic responses are commonly reported in cases of human medical emergency following recreational use of 3,4-methylenedioxymethamphetamine (MDMA, "Ecstasy"), but a precise determination of contributing environmental factors has been elusive given the relative scarcity of threatening and fatal reactions in humans. This study was conducted to determine if elevated physical activity contributes to hyperthermic responses to MDMA in a well controlled animal model. Unrestrained male Wistar rats were monitored with minimally-invasive radiotelemetry techniques following challenge with MDMA $\left(1.0,5.6\right.$ and $10.0 \mathrm{mg} / \mathrm{kg}$, s.c.). Studies were conducted in low $\left(23-25^{\circ} \mathrm{C}\right)$ and high $\left(27^{\circ} \mathrm{C}\right)$ ambient temperature $\left(T_{A}\right)$, with and without access to an activity wheel. The study confirmed dose dependent effects on body temperature, chamber activity and wheel activity which were modified by different $T_{A}$ conditions. Increases in wheel and home chamber activity produced by $10 \mathrm{mg} / \mathrm{kg}$ MDMA increased the magnitude of hyperthermia under $27^{\circ} \mathrm{C} \mathrm{T}$. Furthermore, greater subject mortality was observed in the wheel-access condition compared with the no-wheel condition. These data provide direct evidence that sustained physical activity increases the hyperthermic response to MDMA and that this is associated with increased lethality. This is the first direct experimental confirmation that increased physical activity may be a risk factor for adverse reactions to MDMA in human user populations.

\section{Keywords: thermoregulation; entactogen; exercise; Ecstasy}




\section{INTRODUCTION}

It is well established that disruption of thermoregulation following the administration of 3,4methylenedioxymethamphetamine (MDMA, "Ecstasy") occurs in a variety of laboratory species including monkeys (Banks et al. 2007; Taffe 2012 ; Taffe et al. 2006; Von Huben et al. 2007), pigs (Fiege et al. 2003; Rosa-Neto et al. 2004), rabbits (Pedersen and Blessing 2001), guinea pigs (Saadat et al. 2004), rats (Brown and Kiyatkin 2004; Dafters 1994; Malberg and Seiden 1998) and mice (Carvalho et al. 2002; Fantegrossi et al. 2003). As such, it is possible to use animal models to explore the causes of the relatively infrequent, but severe, MDMA-related human medical emergency and/or death (Mascola et al. 2010) in which hyperthermia is a common observation (Dams et al. 2003; Gillman 1997; Greene et al. 2003; Mallick and Bodenham 1997). It is frequently hypothesized (Parrott 2004) that prolonged physical activity (e.g., dancing) in the rave or club environment interacts with the elevated ambient temperature $\left(T_{A}\right)$ to increase risk of medical emergency but this possibility has not been directly determined in controlled laboratory models. Given that MDMA use patterns are more episodic than patterns for traditional stimulants, and that users are motivated to use scientific results to reduce harm, provision of actionable real-world risk information is likely to result in behavioral change (Taffe 2015). This makes it imperative to rule physical activity in or out as a contributing risk factor and to determine if it interacts with elevated $T_{A}$.

MDMA increases open field locomotion in rats at doses of about $10 \mathrm{mg} / \mathrm{kg}$ of either the racemic mixture or the $\mathrm{S}(+)$ stereoisomer (Gold and Koob 1988; Gold et al. 1988). MDMA may also increase rats' locomotion under certain conditions following doses of 1-3 mg/kg (Baumann et al. 2012; Kehr et al. 2011). Unlike open field activity, the access to an activity wheel can be varied without undue restraint and therefore it can be used as an independent variable to model the presence or absence of sustained physical activity (i.e., the dancing that is a feature of one prominent Ecstasy use environment). In rats, the thermoregulatory effects of MDMA depend on ambient temperature $\left(T_{A}\right)$ with a decrease in body temperature observed at a sufficiently low $\left(\sim 20-23^{\circ} \mathrm{C}\right) \mathrm{T}_{\mathrm{A}}$ and an increase in body temperature at elevated ( 27-30 $\mathrm{C}) \mathrm{T}_{\mathrm{A}}$ (Dafters 1994; Malberg and Seiden 1998). The MDMA dose tends to overlay, rather than adding to or potentating, the effect of $\mathrm{T}_{\mathrm{A}}$ since higher doses can produce hyperthermia under lower $\mathrm{T}_{\mathrm{A}}$ conditions where lower MDMA doses result in hypothermia. Low $\mathrm{T}_{\mathrm{A}}$ is also protective against MDMA-induced lethality in both rats and mice (Fantegrossi et al. 2003; Malberg and Seiden 1998). Interestingly MDMA appears to elevate body temperature across a similar $\mathrm{T}_{\mathrm{A}}$ range in monkeys or humans (Crean et al. 2007; Crean et al. 2006; Freedman et al. 2005; Taffe 2012; Taffe et al. 2006; Von Huben et al. 2007) which suggests that rodent studies conducted at $T_{A}$ which reliably produces hyperthermia, i.e., within the thermoneutral range (Gordon 1990), are most relevant to the human condition.

We have shown in prior work that MDMA increases rats' wheel activity after a $10 \mathrm{mg} / \mathrm{kg}$ dose, but decreases wheel activity after $7.5 \mathrm{mg} / \mathrm{kg}$ and lower doses, when administered in the dark part of the 
circadian cycle under normal laboratory $\mathrm{T}_{\mathrm{A}}\left(\sim 22-23^{\circ} \mathrm{C}\right)$ conditions (Gilpin et al. 2011; Huang et al. 2012). Wheel activity is similarly increased by the prototypical stimulant methamphetamine and the novel cathinone derivative 3,4-methylenedioxypyrovalerone (Huang et al. 2012), which supports the validity of this assay. The Gilpin et al. (2012) study found no difference in the rectal hyperthermia generated by 10 $\mathrm{mg} / \mathrm{kg}$ MDMA when animals had access to the wheel compared with that observed without wheel access, however an apparent increase in mortality rate was found. Since the thermoregulatory response to MDMA in rats depends on the $T_{A}$ in addition to the dose (Dafters 1994; Malberg and Seiden 1998) the present study was conducted to determine if wheel access increases MDMA-induced hyperthermia under differential ambient temperature conditions. A minimally invasive radiotelemetry system, shown to detect alterations of both the activity and body temperature of rats after administration of methamphetamine, 4-methylmethcathinone, $\Delta^{9}$-tetrahydrocannabinol, a-pyrrolidinopentiophenone and 3,4-methylenedioxymethamphetamine (Aarde et al. 2013a; Aarde et al. 2015; Taffe et al. 2015; Wright et al. 2012) (and most specifically $5.6 \mathrm{mg} / \mathrm{kg}$ MDMA, s.c. under a $\mathrm{T}_{\mathrm{A}}$ of $30^{\circ} \mathrm{C}$; (Miller et al. 2013)), was used to reduce potential effects of the stress of the rectal sampling used by Gilpin et al. (2012).

\section{Materials and Methods}

2.1 Animals: Male Wistar rats (Charles River, New York) were housed in a humidity and temperaturecontrolled $\left(22^{\circ} \mathrm{C} \pm 1\right)$ vivarium on a $12 \mathrm{hr}: 12 \mathrm{hr}$ reverse light cycle. Animals were $250-300 \mathrm{~g}$ on arrival at the laboratory. Drug challenge studies were conducted in the animals' dark (active) period. Animals had ad libitum access to food and water throughout the course of the studies. All procedures were conducted under protocols approved by the Institutional Care and Use Committee of The Scripps Research Institute and consistent with the US NIH guidelines for the care and use of laboratory animals (Garber et al. 2011).

2.2 Equipment: Activity wheels (Med Associates Model \#ENV-046; $\sim 35 \mathrm{~cm}$ diameter runway) were attached to the side of a shoebox style home cage modified with a door to provide wheel access. Heating of the experimental rooms was by individual space heaters and verified by a portable thermometer and a probe attached to the telemetry system (Data Sciences International; C10T). Variability of the ambient temperature was $\pm 1^{\circ} \mathrm{C}$ from the target temperature for these studies.

2.3 Radiotelemetry: Radiotelemetry transmitters (Data Sciences International; CTA-F40, TA-F40) were implanted using sterile surgical techniques under anesthesia with an isoflurane/oxygen vapor mixture (isoflurane $5 \%$ induction, 1-3\% maintenance). An incision was made along the abdominal midline posterior to the xyphoid space, just large enough to allow passage of the miniature transmitter which was placed in the abdominal cavity. Absorbable sutures were used to close the abdominal muscle incision and the skin incision was closed with the aforementioned tissue adhesive $\left(3 M^{\mathrm{TM}}\right.$ Vetbond $^{\mathrm{TM}}$ Tissue 
Adhesive; 3M St Paul, MN). A minimum of 7 days was allowed for surgical recovery prior to starting the study. For the first three days of the recovery period, cephazolin $(0.4 \mathrm{~g} / \mathrm{ml} ; 2.0 \mathrm{ml} / \mathrm{kg} \mathrm{sc}$; once daily) and flunixin (2.5 mg/ml; $2.0 \mathrm{ml} / \mathrm{kg} \mathrm{sc}$; once daily) were administered.

Radiotelemetry recordings of body temperature $\left({ }^{\circ} \mathrm{C}\right.$ ) and activity (total counts which are derived from the rate recorded by the software multiplied by the number of minutes in the sampling interval) were made every five minutes via a telemetry receiver plate placed under a normal shoebox style lexan cage. In all studies a response plan for managing excessive hyperthermia was in place. If an animal's temperature exceeded the allowable threshold $\left(42^{\circ} \mathrm{C}\right)$ it was placed on a pad covering a layer of ice in a standard chamber until normative temperature range $\left(36.5-39^{\circ} \mathrm{C}\right)$ was restored for at least an hour. Animals were then monitored periodically up to $\sim 6-8$ hours after the dosing time. Animals that could not maintain normative body temperature or were observed to be unresponsive, immobile and/or moribund this long after dosing were euthanized as a matter of protocol.

2.4 Drugs: The ( \pm )-3,4-methylendioxymethamphetamine $\mathrm{HCl}$ for this study was provided by the US National Institute on Drug Abuse Drug Supply program. Drug doses (expressed as the salt) were diluted in physiological saline and injected subcutaneously in a volume of $\sim 1 \mathrm{ml} / \mathrm{kg}$. Treatment conditions (drug dose, wheel access) were tested in a randomized order across groups with a minimum 3-4 day interval between drug challenges.

2.5 Data analysis: Analysis of the temperature, activity and wheel running data employed analysis of variance (ANOVA) with within-subjects factors of time post-injection. The drug treatment condition with and without wheel access factor was analyzed as between-subjects due to differential subject dropout across treatment conditions. The data were averaged (temperature, wheel quarter rotations) or summated (activity counts) across 30 min intervals for analysis. Any significant ANOVA main effects were followed with post-hoc analysis using Holm-Sidak correction for multiple comparisons. The first post-hoc strategy compared the highest dose of MDMA with Wheel access to all other dose/access conditions within experiment to test the main hypothesis under investigation. The secondary post-hoc strategy tested all dose/wheel access conditions against all other conditions. Analyses were conducted using Prism 6 for Windows (v. 6.02; GraphPad Software, Inc, San Diego CA). Graphs were generated with Excel (Microsoft, Redmond WA) and figures created in Canvas (v.12; ACD Systems of America, Inc, Seattle, WA)

\subsection{Experiments:}

2.6.1 Experiment 1: Effects of 1, 5.6 mg/kg MDMA at $23^{\circ} \mathrm{C}$ Ambient Temperature With and Without Wheel Access 
A group of male Wistar rats $(\mathrm{N}=6 ; 62 \mathrm{wks}$ of age, mean $630 \mathrm{~g})$ were used in this initial experiment. This group had been used in a prior study of the effects of methamphetamine $(1,5.6 \mathrm{mg} / \mathrm{kg}$ s.c., under 20 or $25^{\circ} \mathrm{C}$ ambient temperature conditions) as previously reported (Aarde et al. 2013b). Ambient temperature $\left(\mathrm{T}_{\mathrm{A}}\right)$ was not manipulated recorded but was estimated as about $23^{\circ} \mathrm{C}$ based on the building / facilities thermostat settings. The main goal was to validate the model telemetric monitoring of MDMA responses in the presence and absence of wheel access, as a technical improvement over our prior study (Gilpin et al. 2011), under conditions unlikely to produce threatening hyperthermia. Doses of $0.0,1.0$ and $5.6 \mathrm{mg} / \mathrm{kg}$, s.c., were evaluated with and without wheel access in a randomized order.

\subsubsection{Experiment 2: Effects of 1,5.6 mg/kg MDMA at $25^{\circ} \mathrm{C}$ Ambient Temperature, and $10 \mathrm{mg} / \mathrm{kg}$ MDMA at $23^{\circ} \mathrm{C}$ Ambient Temperature, With and Without Wheel Access}

A group of male Wistar ( $\mathrm{N}=8 ; 20$ wks of age, mean $488 \mathrm{~g}$ body weight at start) were used in these studies. Animals had no drug exposure prior to the start of this study. After first completing the mixed order challenges of 0.0,1.0, $5.6 \mathrm{mg} / \mathrm{kg}$ MDMA s.c. with wheel and no-wheel access conditions under 25 ${ }^{\circ} \mathrm{C}$, the group was next used to evaluate 0.0 vs $10 \mathrm{mg} / \mathrm{kg}$ MDMA s.c. with wheel/no-wheel access conditions in another randomized order, repeated measures design under $23^{\circ} \mathrm{C}$.

\subsubsection{Experiment 3: Effects of 5.6, $10 \mathrm{mg} / \mathrm{kg}$ MDMA at $27^{\circ} \mathrm{C}$ Ambient Temperature, With and Without Wheel Access}

Two different cohorts of male Wistar rats were used, including $\mathrm{N}=10 \sim 40$ wk old animals and $\mathrm{N}=6$ $\sim 20$ wk old animals. The latter group was drug naïve. Subsets of the former group previously participated in the Experiment 2 studies and in pilot investigations of the effects of $5.6 \mathrm{mg} / \mathrm{kg} \mathrm{MDMA}$ and $5.6 \mathrm{mg} / \mathrm{kg}$ MA at $20^{\circ} \mathrm{C} \mathrm{T}_{\mathrm{A}}$ as well as $5.6 \mathrm{mg} / \mathrm{kg}(+)-\mathrm{MDMA}$ vs $5.6 \mathrm{mg} / \mathrm{kg}(-)-\mathrm{MDMA}$ at $27^{\circ} \mathrm{C} \mathrm{T}_{\mathrm{A}}(\mathrm{N}=2)$. Another subset received prior exposure to $1.0,5.6 \mathrm{mg} / \mathrm{kg} 3,4$-methylenedioxyamphetamine $23{ }^{\circ} \mathrm{C} \mathrm{T}_{\mathrm{A}}(\mathrm{N}=2)$. For this study the individuals received $0.0,5.6$ or $10.0 \mathrm{mg} / \mathrm{kg}$ MDMA s.c. with wheel and no-wheel access conditions in a randomized order under $27^{\circ} \mathrm{C}$ ambient.

\section{Results}

\subsection{Mortality}

The 16 rats treated with $10 \mathrm{mg} / \mathrm{kg}$ under $27^{\circ} \mathrm{C} \mathrm{T}$ in the wheel condition (Experiment 3) consisted of 10 from the $\sim 40$ week old group and 6 from the $\sim 20$ week old group; of these, 6 of the older rats and 2 of the younger rats died within $24 \mathrm{~h}$ of injection. In addition, one animal (of 12 participants) was euthanized by protocol after the $5.6 \mathrm{mg} / \mathrm{kg}+$ Wheel Access condition (run before it was scheduled for 10 $\mathrm{mg} / \mathrm{kg}+$ Wheel but after it completed $10 \mathrm{mg} / \mathrm{kg}$ No Wheel successfully); this individual was of the younger age group. Six of the 11 animals which were treated with $10 \mathrm{mg} / \mathrm{kg}$ in the No Wheel condition (all survived) were of the $\sim 40 \mathrm{wk}$ old cohort. The one animal (of 7 treated) who died in the $10 \mathrm{mg} / \mathrm{kg}+$ 
Wheel Access at $23^{\circ} \mathrm{C}$ ambient condition (Experiment 2) was 30 wks of age at the time. Thus it is unlikely that age or participation in prior drug studies had a major qualitative effect on the outcome. The most parsimonious interpretation is that wheel running poses additional risk in rats from $\sim 20$ wk to $\sim 40$ wk of age, regardless of prior drug history.

\subsection{Wheel Activity}

3.2.1 Experiment 1: In the first experiment with ambient temperature under normal building control, but not explicitly monitored or altered, there were no significant effects of drug/wheel treatment condition, of time post-injection, nor of the interaction, on wheel rotations (Figure 1A). One animal's wheel data after vehicle challenge was not collected due to equipment malfunction thus the analysis was between-groups for this measure.

A.

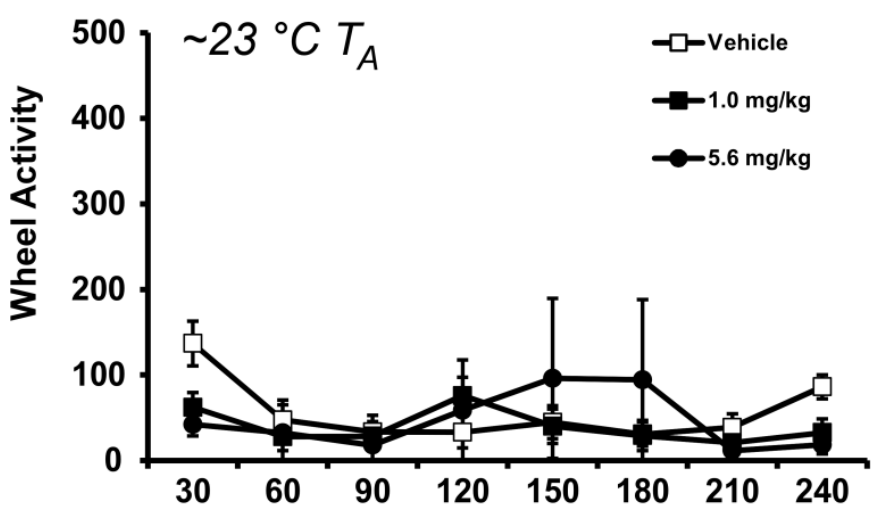

C.

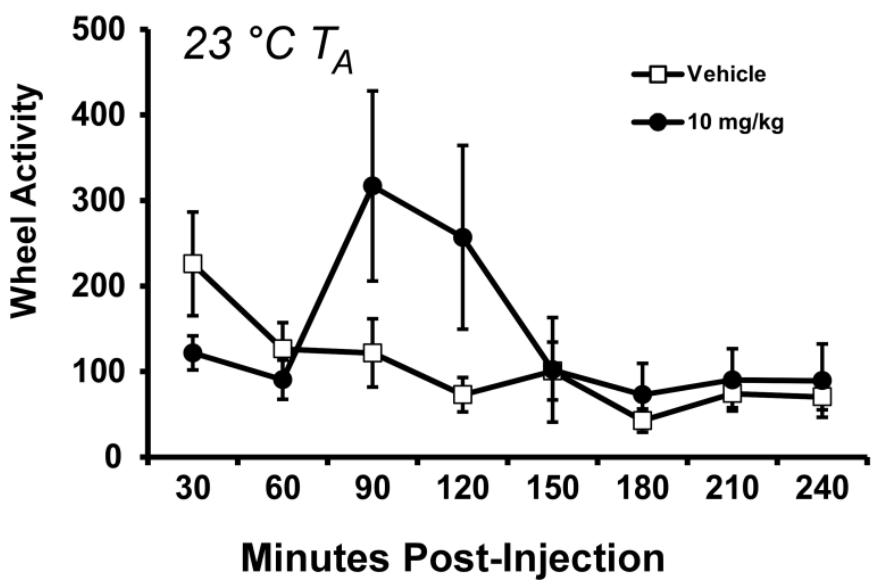

B.

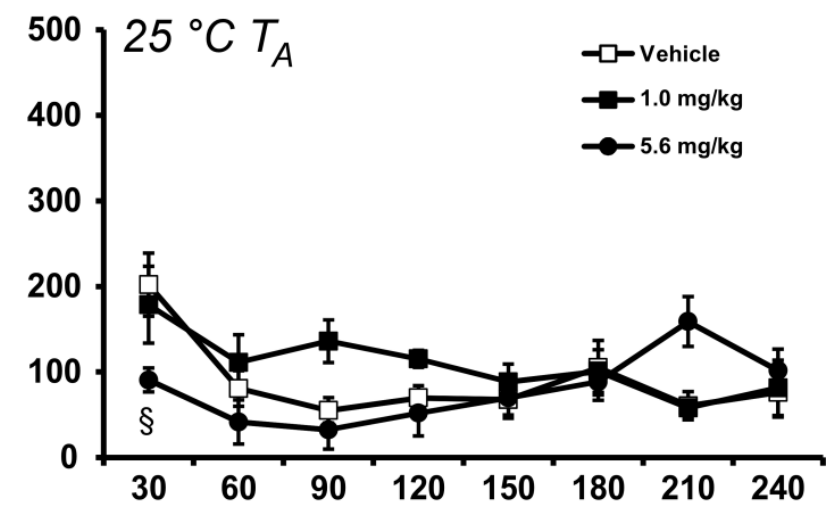

D.

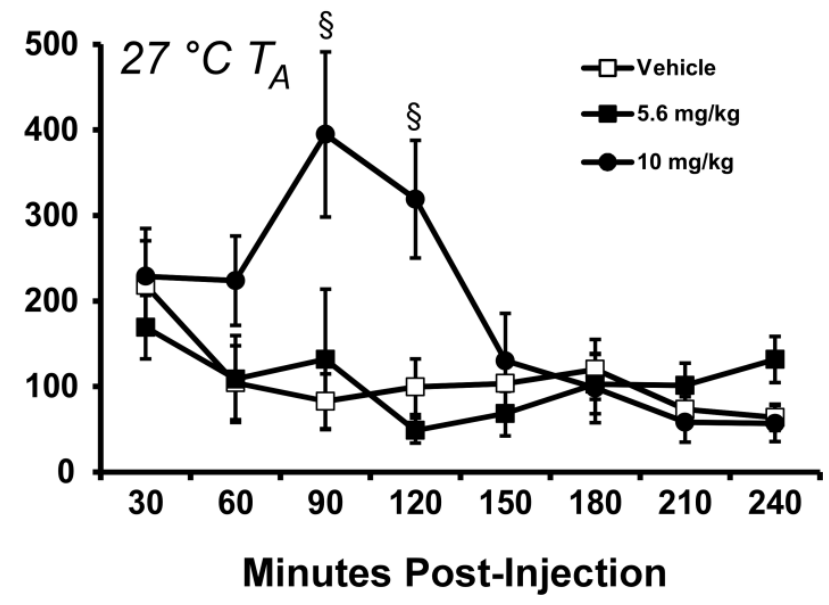

Figure 1. Mean wheel activity (average quarter rotations) for $\boldsymbol{A})$ Rats $(N=5-6)$ following challenge with Vehicle or $\operatorname{MDMA}\left(5.6,10 \mathrm{mg} / \mathrm{kg}\right.$, s.c.) under normal laboratory $\left(\sim 23^{\circ} \mathrm{C}\right) T_{A}$ conditions; $\left.B\right)$ Rats $(N=7-8)$ following challenge with Vehicle or MDMA (5.6, $10 \mathrm{mg} / \mathrm{kg}$, s.C.) under $25^{\circ} \mathrm{C} T_{A}$; C) challenge with Vehicle or $10 \mathrm{mg} / \mathrm{kg} \mathrm{MDMA}$, s.C., under $23^{\circ} \mathrm{C} T_{A}$; or $\left.D\right)$ Rats ( $N=10-14$ ) following challenge with Vehicle or MDMA (5.6, $10 \mathrm{mg} / \mathrm{kg}$, s. C.) under $27^{\circ} \mathrm{C}$ $T_{A}$. Significant differences between the highest MDMA dose and all other conditions at a given time post-injection is indicated by \&. Bars indicate SEM. 
3.2.2 Experiment 2: A replication of the lower-dose experiment was then performed with the $\mathrm{T}_{\mathrm{A}}$ controlled and monitored to $25^{\circ} \mathrm{C}$ in a group $(\mathrm{N}=8)$ of naïve male rats. The ANOVA confirmed that wheel activity was significantly changed (Figure $1 B$ ) by time post-injection $[F(7,119)=6.03 ; P<0.0001]$ and by the interaction of drug/wheel treatment condition with time post-injection $[F(14,119)=4.12 ; P<0.0001]$. The post-hoc test further confirmed wheel activity was lower in the $5.6 \mathrm{mg} / \mathrm{kg}$ MDMA condition compared with the Vehicle (30 min post-injection) and $1.0 \mathrm{mg} / \mathrm{kg}$ MDMA (30, $90 \mathrm{~min}$ post-injection) conditions. The group was next challenged with vehicle or $10 \mathrm{mg} / \mathrm{kg}$ MDMA with $\mathrm{T}_{\mathrm{A}}$ controlled at $23^{\circ} \mathrm{C}$ (Figure 1C). One animal from the group was lost prior to this set of challenges for reasons unrelated to these experimental treatments, thus $\mathrm{N}=7$ for most of the high-dose MDMA / $23^{\circ} \mathrm{C} \mathrm{T}_{\mathrm{A}}$ study. As noted under section 3.1 , one of the remaining seven animals died after the $10 \mathrm{mg} / \mathrm{kg}$ MDMA Wheel access condition prior to participating in its last condition (10 mg/kg MDMA / No Wheel) thus analysis is between subjects. In this case the ANOVA confirmed that wheel activity was significantly changed across time post-injection [F ( 7 , $84)=2.98 ; P<0.01]$ and determined by the interaction of drug/wheel treatment condition with time postinjection $[F(7,84)=2.50 ; P<0.05]$, however the post-hoc test did not confirm any significant differences in wheel activity between drug conditions at any specific times post-injection.

\subsubsection{Experiment 3: Out of the $\mathrm{N}=16$ rats used in this study, $\mathrm{N}=14$ completed the $5.6 \mathrm{mg} / \mathrm{kg}$ MDMA / No} Wheel and the $10 \mathrm{mg} / \mathrm{kg}$ MDMA / Wheel conditions, N=13 completed the Vehicle / Wheel condition, $\mathrm{N}=11$ completed the Vehicle / No Wheel, $5.6 \mathrm{mg} / \mathrm{kg}$ MDMA / Wheel and $10 \mathrm{mg} / \mathrm{kg}$ MDMA / No Wheel conditions due to the randomization of treatment conditions and subject mortality, as described in Section 3.1. Consequently the analysis treated drug/wheel condition as a between-groups factor since not all subjects were represented in all conditions. Wheel activity was again affected by drug treatment and time post-injection (Figure 1D) in this experiment and the ANOVA confirmed a significant effect of time post-injection $[F(7,175)=6.06 ; \mathrm{P}<0.0001]$ and the interaction $[F(7,175)=4.75 ; \mathrm{P}<0.0001]$ wheel activity. The post-hoc test confirmed that wheel activity was higher in the $10 \mathrm{mg} / \mathrm{kg}$ MDMA treatment compared with vehicle 90-120 min after injection.

Together the wheel data confirm and extend our prior results (Gilpin et al. 2011) by showing that wheel activity is suppressed or unchanged by doses of MDMA up to $5.6 \mathrm{mg} / \mathrm{kg}$ and increased by 10 $\mathrm{mg} / \mathrm{kg}$. The stimulant effect of $10 \mathrm{mg} / \mathrm{kg}$ MDMA on wheel activity was approximately equivalent from 23$27^{\circ} \mathrm{C} \mathrm{T}_{\mathrm{A}}$.

\subsection{Body Temperature}

3.3.1 Experiment 1: Body temperature was decreased by MDMA in a dose, time and wheel-access dependent manner (Figure 2A) as confirmed by a main effect of time post-injection $[F(7,35)=4.76$; $P<$ 0.001 ) and of the interaction of drug/wheel treatment condition with time post-injection $[F(35,175)=$ 
3.48; $\mathrm{P}<0.0001$ ) in the ANOVA. The post-hoc test confirmed temperature was lower in the $5.6 \mathrm{mg} / \mathrm{kg}$ MDMA / Wheel condition compared with all other conditions at $30 \mathrm{~min}$ post-injection and compared with all other conditions except the $5.6 \mathrm{mg} / \mathrm{kg}$ MDMA / No Wheel condition at 60 minutes post-injection.

3.3.2 Experiment 2: Body temperature was decreased by drug treatment under $25^{\circ} \mathrm{C} \mathrm{T}_{\mathrm{A}}$ (Figure 2B) in this group and the ANOVA confirmed a main effect of time post-injection $[F(7,287)=9.80 ; P<0.0001]$ and of the interaction of drug/wheel treatment condition with time post-injection $[F(35,287)=4.61 ; P<$ 0.0001]. The post-hoc test confirmed temperature was lower in the $5.6 \mathrm{mg} / \mathrm{kg}$ MDMA / Wheel condition compared with all other conditions at 60-90 min post-injection. (One animal's temperature data was lost in the $1.0 \mathrm{mg} / \mathrm{kgMDMA}$ / Wheel condition due to technical error thus analysis was between-subjects.)

Body temperature was increased by $10 \mathrm{mg} / \mathrm{kg}$ MDMA under $23^{\circ} \mathrm{C} \mathrm{T}_{\mathrm{A}}$ (Figure 2C) as confirmed by significant effects of time post-injection $[F(7,161)=4.46 ; P<0.0005]$ and of the interaction of $\mathrm{drug} /$ wheel treatment condition with time post-injection $[\mathrm{F}(21,161)=5.14 ; \mathrm{P}<0.0001]$ in the ANOVA.

A.

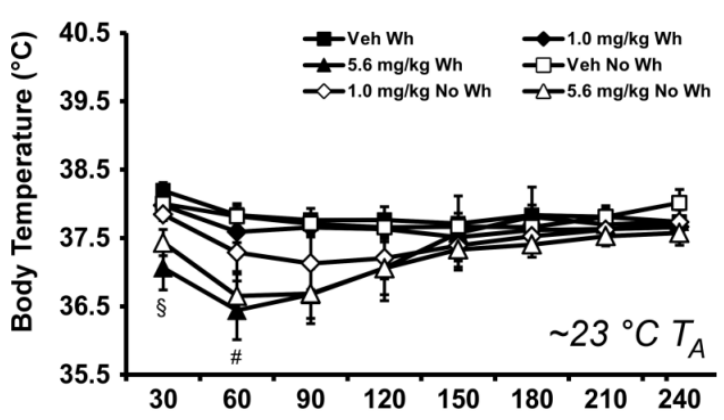

C.



B.

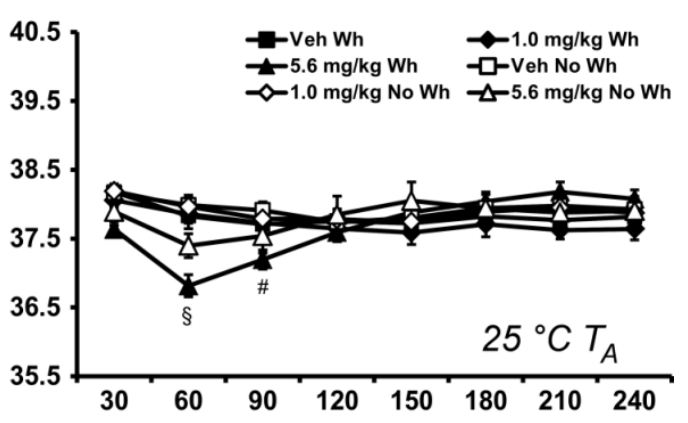

D.



Figure 2. Mean temperature for $\boldsymbol{A})$ Rats $(N=6)$ following challenge with $0,5.6$ or $10 \mathrm{mg} / \mathrm{kg}$ MDMA under normal laboratory $\left(-23^{\circ} \mathrm{C}\right) T_{A}$ conditions; $\left.B\right)$ Rats $(N=6-8)$ following challenge with $0,5.6$ or $10 \mathrm{mg} / \mathrm{kg} \mathrm{MDMA}$ under $25^{\circ} \mathrm{C}$ $T_{A}$; C) challenge with 0 or $10 \mathrm{mg} / \mathrm{kg} \mathrm{MDMA}$ under $23^{\circ} \mathrm{C} T_{A}$; or $\left.\mathrm{D}\right)$ Rats $(\mathrm{N}=10$-14) following challenge with $0,5.6$ or $10 \mathrm{mg} / \mathrm{kg}$ MDMA under $27^{\circ} \mathrm{C} T_{A}$. Drug treatments were repeated twice to incorporate conditions with and without wheel (Wh) access. Significant differences between the highest MDMA dose with Wheel access and all other conditions is indicated by \&; and between the highest MDMA dose with Wheel and all other conditions except the corresponding highest MDMA / No-Wheel condition by \#. Bars indicate SEM. 
The post-hoc test confirmed that temperature was higher after $10 \mathrm{mg} / \mathrm{kg}$ MDMA was administered with Wheel access compared with either Wheel (120-210 min post-injection) or No Wheel (120-180 min post-injection) vehicle conditions but not the $10 \mathrm{mg} / \mathrm{kg}$ MDMA / No Wheel condition.

3.3.3 Experiment 3: The analysis treated drug/wheel condition as a between-groups factor since not all subjects were represented in all conditions, as outlined in Section 3.2.3, above. One individual's 240 min post-injection value was a duplication of the 210 value in the $10 \mathrm{mg} / \mathrm{kg}+$ Wheel condition due to a missing value (due to cooling the animal per protocol). The ANOVA confirmed a main effect of Drug/Wheel Condition $[F(3,45)=10.67$; $\mathrm{P}<0.0001]$; of time post-injection $[F(7,315)=10.99 ; \mathrm{P}<$ $0.0001]$ and the interaction $[F(21,315)=12.23 ; P<0.0001]$ on body temperature (Figure 2D). The posthoc test confirmed that temperature was higher in the $10 \mathrm{mg} / \mathrm{kg}$ MDMA / Wheel condition compared with all other conditions from 180-240 min post-injection and compared with all other conditions except 10 $\mathrm{mg} / \mathrm{kg}$ MDMA / No Wheel condition from 120-150 minutes post-injection.

\subsection{Activity}

3.4.1 Experiment 1: There were no significant effects of drug treatment / wheel access condition or time post-injection on activity counts measured by the telemetry system in this experiment (Figure 3A).

3.4.2 Experiment 2: The activity in the home chamber was increased by both MDMA injection and wheel access (Figure 3B) when studies were conducted under $25^{\circ} \mathrm{C} \mathrm{T}_{\mathrm{A}}$. The ANOVA confirmed a main effect of Drug/Wheel Condition [F $(5,41)=18.57 ; \mathrm{P}<0.0001]$, of time post-injection $[\mathrm{F}(7,287)=18.76 ; \mathrm{P}<$ $0.0001]$ and the interaction $[F(35,287)=2.15 ; P<0.0005]$ on home chamber activity. The post-hoc test confirmed that activity was increased relative to the respective vehicle wheel condition after $5.6 \mathrm{mg} / \mathrm{kg}$ MDMA was administered either with (60-90, 240 minutes post-injection) or without (30-120 minutes postinjection) Wheel access. Likewise, activity differed between 1.0 and $5.6 \mathrm{mg} / \mathrm{kg}$ MDMA treatments in Wheel (240 minutes post-injection) and No Wheel (60-150 minutes post-injection) conditions. Home chamber activity was also higher in the Wheel vs No Wheel Conditions after Vehicle (30-60, 180 minutes post-injection), $1.0 \mathrm{mg} / \mathrm{kg}$ MDMA (30-90, 150 minutes post-injection) and 5.6 mg/kg MDMA (30, 180-240 minutes post-injection).

The ANOVA confirmed a Main effect of Drug/Wheel Condition $[F(3,23)=9.67 ; P<0.0005]$; of time post-injection $[F(7,161)=4.80 ; P<0.0001]$ and the interaction $[F(21,161)=2.09 ; P<0.01]$ on home chamber activity (Figure $3 \mathbf{C}$ ). The post-hoc test confirmed that activity was increased relative to the respective wheel condition vehicle 90-120 min after $10.0 \mathrm{mg} / \mathrm{kg}$ MDMA either with or without Wheel access. Activity was also higher $90 \mathrm{~min}$ after $10 \mathrm{mg} / \mathrm{kg}$ MDMA was administered in the Wheel access condition compared with the same dose without wheel access. 
3.4.3 Experiment 3: Chamber activity measured by telemetry was increased by both wheel access and MDMA administration under $27^{\circ} \mathrm{C} \mathrm{T}_{\mathrm{A}}$ (Figure 3D). The ANOVA confirmed a Main effect of Drug/Wheel Condition $[F(5,69)=22.05 ; P<0.0001]$; of time post-injection $[F(7,483)=24.05 ; P<0.0001]$ and the interaction $[F(35,483)=5.41 ; \mathrm{P}<0.0001]$ on home chamber activity. The Holm-Sidak post-hoc confirmed that activity was higher after $10 \mathrm{mg} / \mathrm{kg}$ MDMA compared with the respective vehicle treatment

A.

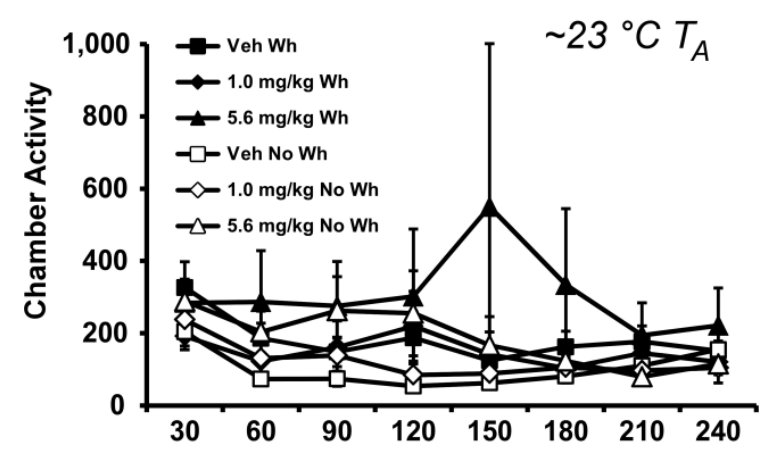

C.

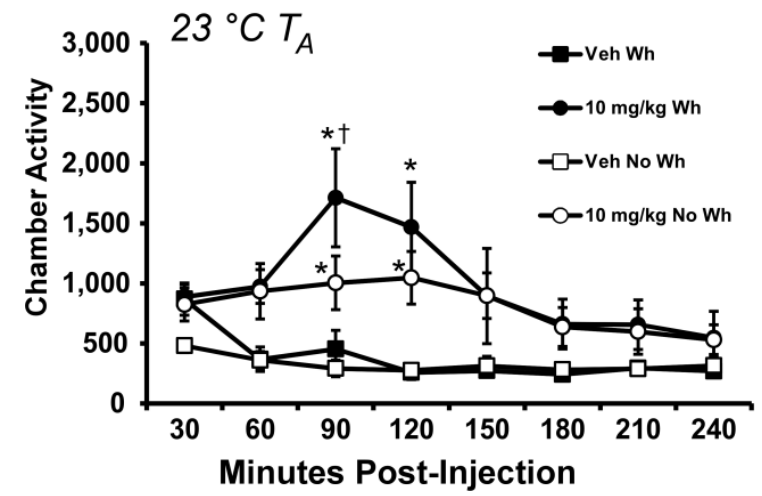

B.

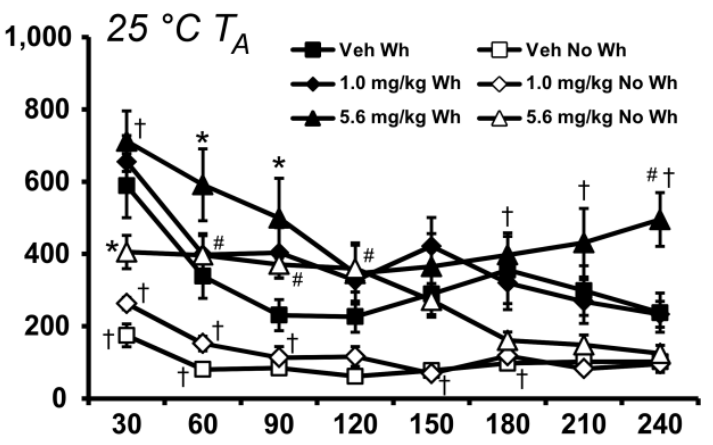

D.

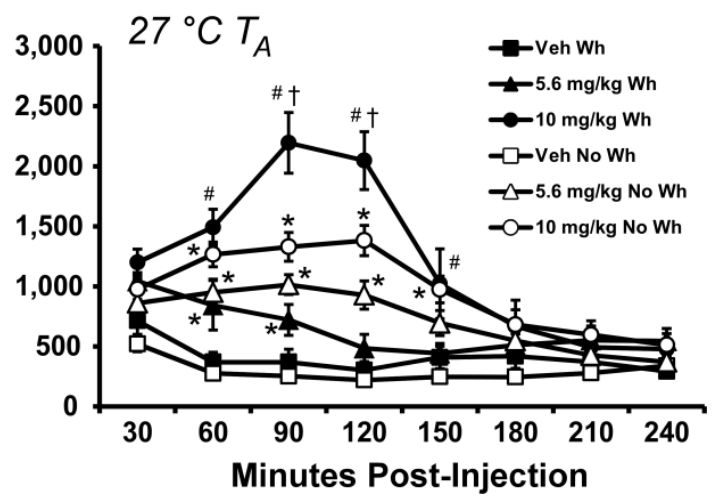

Figure 3. Mean chamber activity for $A)$ Rats $(N=6)$ following challenge with $0,5.6$ or $10 \mathrm{mg} / \mathrm{kg}$ MDMA under normal laboratory $\left(-23^{\circ} \mathrm{C}\right) T_{A}$ conditions; $\left.B\right)$ Rats $(N=7-8)$ following challenge with $0,5.6$ or $10 \mathrm{mg} / \mathrm{kg} \mathrm{MDMA}$ under $\left.25^{\circ} \mathrm{C} T_{A} ; \mathrm{C}\right)$ Rats $(\mathrm{N}=6-7)$ challenge with 0 or $10 \mathrm{mg} / \mathrm{kg}$ MDMA under $23^{\circ} \mathrm{C} T_{A}$; or $\left.\mathrm{D}\right)$ Rats $(\mathrm{N}=10-14)$ following challenge with $0,5.6$ or $10 \mathrm{mg} / \mathrm{kg} M D M A$ under $27^{\circ} \mathrm{C} T_{A}$. Drug treatments were repeated twice to incorporate conditions with and without wheel (Wh) access. Note scale change between upper and lower panels. Significant differences from Vehicle $\left(^{*}\right)$ or Vehicle and $1.0 \mathrm{mg} / \mathrm{kg}(\#)$ within Wheel access conditions are indicated. Significant differences between the Wheel access conditions within Veh/MDMA dose are indicated by $\dagger$. Bars indicate SEM.

60-150 min post-injection in the No Wheel and Wheel access conditions. The activity was also higher 90$120 \mathrm{~min}$ after injection of $10 \mathrm{mg} / \mathrm{kg}$ MDMA when the Wheel was available compared to the same dose in the No Wheel condition. In addition, the post-hoc test confirmed that activity was higher after $5.6 \mathrm{mg} / \mathrm{kg}$ MDMA compared with the respective vehicle condition when administered with Wheel access (60-90 min post-injection) or with No Wheel (60-120 min post-injection). Activity also differed significantly between 5.6 and $10 \mathrm{mg} / \mathrm{kg}$ MDMA treatments with Wheel access (60-150 min post-injection) but not under No Wheel conditions. 


\section{Discussion}

This study examined the effect of wheel activity on the thermoregulatory effects of MDMA. The majority of prior studies of MDMA-induced activity in rodent models has reported spontaneous home chamber or open field activity changes after MDMA and, as such, could not make firm conclusions about the role of physical exertion. The manipulation of wheel access in the present study was successful in changing activity levels on the wheel and also in terms of chamber movement. The results show that higher levels of activity during the post-drug interval increases the magnitude of hyperthermia and the likelihood of fatality, particularly when a high dose is administered under ambient temperature $\left(T_{A}\right)$ that is thermoneutral for rats (Gordon 1990). Specifically, this study identified a threshold of approximately 27 ${ }^{\circ} \mathrm{C}$ to produce interactive effects of wheel activity to potentiate the hyperthermia caused by $10 \mathrm{mg} / \mathrm{kg}$ MDMA. Wheel access was also associated with an increase in 24-h mortality rate, consistent with our prior report (Gilpin et al. 2011). The $27^{\circ} \mathrm{C} \mathrm{T}_{\mathrm{A}}$ threshold reported here for adverse effects of voluntary exercise is considerably lower than the $32{ }^{\circ} \mathrm{C} \mathrm{T}_{\mathrm{A}}$ reported to interact with forced running to exaggerate hyperthermia induced by $3 \mathrm{mg} / \mathrm{kg}$ MDMA (Tao et al. 2015). Additional work has shown that under $32{ }^{\circ} \mathrm{C}$ $\mathrm{T}_{\mathrm{A}} 7.5 \mathrm{mg} / \mathrm{kg}$ MDMA, i.v., slightly increased the rate of gain, but not the eventual magnitude, of hyperthermia generated by forced treadmill activity in male rats (Zaretsky et al. 2015). The $32{ }^{\circ} \mathrm{C} \mathrm{T}_{\mathrm{A}}$ used in those two prior studies is likely to be above the thermoneutral range for rats (Gordon 1990) and is therefore less likely to generalize to real world conditions for humans (McNeill and Parsons) compared with the present investigation.

The fact that locomotor activity measured by the telemetry was higher in the wheel access versus the no wheel condition after $10 \mathrm{mg} / \mathrm{kg}$ MDMA (and $5.6 \mathrm{mg} / \mathrm{kg}$ MDMA under $25^{\circ} \mathrm{C} \mathrm{T}_{\mathrm{A}}$ ) was unexpected since the a priori assumption was that time on the wheel would decrease time available for movement in the chamber. This result may potentially be attributed to an increase in locomotion due to repeated entry and exit from the wheel or perhaps a non-specific increase in general activity. For interpretive purposes within the present study, this outcome shows that physical activity of the rats during the wheel access condition may have increased even more than is reflected in the wheel rotations. Importantly, while wheel activity after $5.6 \mathrm{mg} / \mathrm{kg}$ MDMA at $25^{\circ} \mathrm{C} \mathrm{T}$, was less than in the related vehicle condition as in our prior work (Gilpin et al. 2011; Huang et al. 2012), chamber locomotor activity was greater. Overall, MDMA-associated increases in chamber activity were dose-dependent within each wheel access condition, further reinforcing the validity of the model.

In our prior study (Gilpin et al. 2011) 3/10 individuals died after $10 \mathrm{mg} / \mathrm{kg} \mathrm{MDMA}$ at $\mathrm{a} \sim 22^{\circ} \mathrm{C}$ ambient temperature. In two cases these individuals experienced $10 \mathrm{mg} / \mathrm{kg}$ with wheel access as the first condition, exhibited the highest temperature changes recorded along with high rates of running and died thereafter. In one case, the individual died after $10 \mathrm{mg} / \mathrm{kg}$ w/o wheel access. The present data further 
indicate that wheel access following $10 \mathrm{mg} / \mathrm{kg}$ MDMA enhances lethality, particularly as the ambient temperature increases. More precise delineation of lethality thresholds and mechanisms are not possible from this study, since it was not designed with death as an endpoint. A cooling protocol with humane euthanasia for animals that could not be stabilized was in place and thus experimental mortality was a mixture of euthanized animals, those that died before temperature could be normalized and individuals who were stable for hours but were nevertheless found dead overnight. These outcomes suggest that multiple mechanisms of fatality may result and justify further investigation into the role exercise plays in MDMA-associated fatality.

One minor limitation to the present results is the repeated measures design. Inevitably the fact that the experiments were conducted in groups of animals who differed in precise age and the number of prior drug challenges under various treatment conditions means some caution is warranted.

Nevertheless, the results were internally consistent and were congruent with prior observations in many particulars. We previously showed that $5.6 \mathrm{mg} / \mathrm{kg}$ MDMA, i.p., suppresses wheel activity whereas 10.0 $\mathrm{mg} / \mathrm{kg}$ increases wheel activity under normal laboratory $\mathrm{T}_{\mathrm{A}}\left(\sim 22^{\circ} \mathrm{C}\right)$ conditions (Gilpin et al. 2011), similar to Figure 1B. In that study only $10 \mathrm{mg} / \mathrm{kg}$ MDMA, i.p., caused a significant elevation of body temperature, consistent with the present effects. We have also shown that $5.6 \mathrm{mg} / \mathrm{kg}$ MDMA, s.c., increases telemetered home cage activity and body temperature under $30{ }^{\circ} \mathrm{C} \mathrm{T}_{\mathrm{A}}$ (Miller et al. 2013) which is here anticipated by the change from a hypothermia to a slight temperature increase cased by $5.6 \mathrm{mg} / \mathrm{kg}$ MDMA across the $25-27^{\circ} \mathrm{C} \mathrm{T}_{\mathrm{A}}$ range (Figure 2B,D). Thus, the consistency with prior observations suggests that the repeated measures design of this investigation did not play a meaningful role in the outcome.

\section{Conclusions}

In conclusion this study demonstrates that spontaneous locomotor activity on a running wheel can increase the mean body temperature changes observed following the administration of MDMA. This was only the case for a dose that consistently elevated locomotor activity both in the home cage and on the wheel and when MDMA was administered at $27^{\circ} \mathrm{C}$ ambient temperature. We did not observe this synergy of MDMA with wheel activity when administered at $23{ }^{\circ} \mathrm{C}$ or in our prior study of $10 \mathrm{mg} / \mathrm{kg}$ MDMA (Gilpin et al. 2011) administered at a similarly low ambient temperature. This study therefore provides the first experimental demonstration that physical exercise interacts with the effects of MDMA to produce adverse physiological and even lethal consequences. 


\section{Role of Funding Source}

This work was supported by USPHS grants DA018418, DA024105 and DA024705; the NIH/NIDA had no further role in study design; in the collection, analysis and interpretation of data; in the writing of the report; or in the decision to submit the paper for publication.

\section{Contributors}

M.A.T. designed the study which was implemented by research technical staff of the laboratory. Statistical analysis of the data, creation of figures and manuscript drafting was conducted by M.A.T.

\section{Conflict of Interest}

The author does not have any financial or other conflicts of interest to declare for this work.

\section{Acknowledgements}

The author is grateful to Sophia A. Vandewater and Glen Dickinson for expert technical assistance. This is manuscript \#29272 from The Scripps Research Institute. 


\section{References Cited}

Aarde SM, Angrish D, Barlow DJ, Wright MJ, Jr., Vandewater SA, Creehan KM, Houseknecht KL, Dickerson TJ, Taffe MA (2013a) Mephedrone (4-methylmethcathinone) supports intravenous selfadministration in Sprague-Dawley and Wistar rats. Addict Biol 18: 786-99

Aarde SM, Creehan KM, Vandewater SA, Dickerson TJ, Taffe MA (2015) In vivo potency and efficacy of the novel cathinone alpha-pyrrolidinopentiophenone and 3,4-methylenedioxypyrovalerone: selfadministration and locomotor stimulation in male rats. Psychopharmacology (Berl)

Aarde SM, Huang PK, Creehan KM, Dickerson TJ, Taffe MA (2013b) The novel recreational drug 3,4methylenedioxypyrovalerone (MDPV) is a potent psychomotor stimulant: self-administration and locomotor activity in rats. Neuropharmacology 71: 130-40

Banks ML, Sprague JE, Kisor DF, Czoty PW, Nichols DE, Nader MA (2007) Ambient temperature effects on 3,4-methylenedioxymethamphetamine-induced thermodysregulation and pharmacokinetics in male monkeys. Drug Metab Dispos 35: 1840-5

Baumann MH, Ayestas MA, Jr., Partilla JS, Sink JR, Shulgin AT, Daley PF, Brandt SD, Rothman RB, Ruoho AE, Cozzi NV (2012) The designer methcathinone analogs, mephedrone and methylone, are substrates for monoamine transporters in brain tissue. Neuropsychopharmacology 37: 1192203

Brown PL, Kiyatkin EA (2004) Brain hyperthermia induced by MDMA (ecstasy): modulation by environmental conditions. Eur J Neurosci 20: 51-8

Carvalho M, Carvalho F, Remiao F, de Lourdes Pereira M, Pires-das-Neves R, de Lourdes Bastos M (2002) Effect of 3,4-methylenedioxymethamphetamine ("ecstasy") on body temperature and liver antioxidant status in mice: influence of ambient temperature. Arch Toxicol 76: 166-72

Crean RD, Davis SA, Taffe MA (2007) Oral administration of (+/-)3,4-methylenedioxymethamphetamine and $(+)$ methamphetamine alters temperature and activity in rhesus macaques. Pharmacol Biochem Behav

Crean RD, Davis SA, Von Huben SN, Lay CC, Katner SN, Taffe MA (2006) Effects of (+/-)3,4methylenedioxymethamphetamine, (+/-)3,4-methylenedioxyamphetamine and methamphetamine on temperature and activity in rhesus macaques. Neuroscience 142: 515-25

Dafters RI (1994) Effect of ambient temperature on hyperthermia and hyperkinesis induced by 3,4methylenedioxymethamphetamine (MDMA or "ecstasy") in rats. Psychopharmacology (Berl) 114: $505-8$

Dams R, De Letter EA, Mortier KA, Cordonnier JA, Lambert WE, Piette MH, Van Calenbergh S, De Leenheer AP (2003) Fatality due to combined use of the designer drugs MDMA and PMA: a distribution study. J Anal Toxicol 27: 318-22 
Fantegrossi WE, Godlewski T, Karabenick RL, Stephens JM, Ullrich T, Rice KC, Woods JH (2003) Pharmacological characterization of the effects of 3,4-methylenedioxymethamphetamine ("ecstasy") and its enantiomers on lethality, core temperature, and locomotor activity in singly housed and crowded mice. Psychopharmacology (Berl) 166: 202-11

Fiege M, Wappler F, Weisshorn R, Gerbershagen MU, Menge M, Schulte Am Esch J (2003) Induction of Malignant Hyperthermia in Susceptible Swine by 3,4-Methylenedioxymethamphetamine ("Ecstasy"). Anesthesiology 99: 1132-1136

Freedman RR, Johanson CE, Tancer ME (2005) Thermoregulatory effects of 3,4methylenedioxymethamphetamine (MDMA) in humans. Psychopharmacology (Berl) 183: 248-56

Garber JC, Barbee RW, Bielitzki JT, Clayton LA, Donovan JC, Hendriksen CFM, Kohn DF, Lipman NS, Locke PA, Melcher J, Quimby FW, Turner PV, Wood GA, Wurbel H (2011) Guide for the Care and Use of Laboratory Animals, 8th Edition. National Academies Press, National Academies Press

Gillman PK (1997) Ecstasy, serotonin syndrome and the treatment of hyperpyrexia. Med J Aust 167 : 109, 111

Gilpin NW, Wright MJ, Jr., Dickinson G, Vandewater SA, Price JU, Taffe MA (2011) Influences of activity wheel access on the body temperature response to MDMA and methamphetamine. Pharmacol Biochem Behav 99: 295-300

Gold LH, Koob GF (1988) Methysergide potentiates the hyperactivity produced by MDMA in rats. Pharmacol Biochem Behav 29: 645-8

Gold LH, Koob GF, Geyer MA (1988) Stimulant and hallucinogenic behavioral profiles of 3,4methylenedioxymethamphetamine and $\mathrm{N}$-ethyl-3,4-methylenedioxyamphetamine in rats. J Pharmacol Exp Ther 247: 547-55

Gordon CJ (1990) Thermal biology of the laboratory rat. Physiol Behav 47: 963-91

Greene SL, Dargan PI, O'Connor N, Jones AL, Kerins M (2003) Multiple toxicity from 3,4methylenedioxymethamphetamine ("ecstasy"). Am J Emerg Med 21: 121-4

Huang PK, Aarde SM, Angrish D, Houseknecht KL, Dickerson TJ, Taffe MA (2012) Contrasting effects of d-methamphetamine, 3,4-methylenedioxymethamphetamine, 3,4-methylenedioxypyrovalerone, and 4-methylmethcathinone on wheel activity in rats. Drug Alcohol Depend 126: 168-75

Kehr J, Ichinose F, Yoshitake S, Goiny M, Sievertsson T, Nyberg F, Yoshitake T (2011) Mephedrone, compared to MDMA (ecstasy) and amphetamine, rapidly increases both dopamine and serotonin levels in nucleus accumbens of awake rats. $\mathrm{Br} \mathrm{J}$ Pharmacol

Malberg JE, Seiden LS (1998) Small changes in ambient temperature cause large changes in 3,4methylenedioxymethamphetamine (MDMA)-induced serotonin neurotoxicity and core body temperature in the rat. J Neurosci 18: 5086-94 
Mallick A, Bodenham AR (1997) MDMA induced hyperthermia: a survivor with an initial body temperature of 42.9 degrees C. J Accid Emerg Med 14: 336-8

Mascola L, Dassey D, Fogleman S, Paulozzi L, Reed CG (2010) Ecstasy overdoses at a New Year's Eve rave--Los Angeles, California, 2010. MMWR Morb Mortal Wkly Rep 59: 677-81

McNeill M, Parsons K HEAT STRESS IN NIGHT-CLUBS [cited] Available from http://ecstasy.org/info/res9.html

Miller ML, Creehan KM, Angrish D, Barlow DJ, Houseknecht KL, Dickerson TJ, Taffe MA (2013) Changes in ambient temperature differentially alter the thermoregulatory, cardiac and locomotor stimulant effects of 4-methylmethcathinone (mephedrone). Drug Alcohol Depend 127: 248-53

Parrott AC (2004) MDMA (3,4-Methylenedioxymethamphetamine) or ecstasy: the neuropsychobiological implications of taking it at dances and raves. Neuropsychobiology 50: 329-35

Pedersen NP, Blessing WW (2001) Cutaneous vasoconstriction contributes to hyperthermia induced by 3,4-methylenedioxymethamphetamine (ecstasy) in conscious rabbits. J Neurosci 21: 8648-54

Rosa-Neto P, Olsen AK, Gjedde A, Watanabe H, Cumming P (2004) MDMA-evoked changes in cerebral blood flow in living porcine brain: correlation with hyperthermia. Synapse 53: 214-21

Saadat KS, Elliott JM, Colado MI, Green AR (2004) Hyperthermic and neurotoxic effect of 3,4methylenedioxymethamphetamine (MDMA) in guinea pigs. Psychopharmacology (Berl) 173: 4523

Taffe MA (2012) Delta9-Tetrahydrocannabinol attenuates MDMA-induced hyperthermia in rhesus monkeys. Neuroscience 201: 125-33

Taffe MA (2015) Drug abuse scientists should use social media to engage the public because their primary translational product is information. Drug Alcohol Depend 154: 315-9

Taffe MA, Creehan KM, Vandewater SA (2015) Cannabidiol fails to reverse hypothermia or locomotor suppression induced by Delta(9) -tetrahydrocannabinol in Sprague-Dawley rats. Br J Pharmacol 172: 1783-91

Taffe MA, Lay CC, Von Huben SN, Davis SA, Crean RD, Katner SN (2006) Hyperthermia induced by 3,4-methylenedioxymethamphetamine in unrestrained rhesus monkeys. Drug Alcohol Depend 82: 276-81

Tao R, Shokry IM, Callanan JJ, Adams HD, Ma Z (2015) Mechanisms and environmental factors that underlying the intensification of 3,4-methylenedioxymethamphetamine (MDMA, Ecstasy)-induced serotonin syndrome in rats. Psychopharmacology (Berl) 232: 1245-60

Von Huben SN, Lay CC, Crean RD, Davis SA, Katner SN, Taffe MA (2007) Impact of ambient temperature on hyperthermia induced by (+/-)3,4-methylenedioxymethamphetamine in rhesus macaques. Neuropsychopharmacology 32: 673-81

Wright MJ, Jr., Angrish D, Aarde SM, Barlow DJ, Buczynski MW, Creehan KM, Vandewater SA, Parsons LH, Houseknecht KL, Dickerson TJ, Taffe MA (2012) Effect of ambient temperature on the 
thermoregulatory and locomotor stimulant effects of 4-methylmethcathinone in Wistar and Sprague-Dawley rats. PLoS One 7: e44652

Zaretsky DV, Zaretskaia MV, Durant PJ, Rusyniak DE (2015) Treadmill running restores MDMAmediated hyperthermia prevented by inhibition of the dorsomedial hypothalamus. Brain Res 1608: $75-81$ 